EMBRYARIDDLE
Aeronautical University

SCHOLARLY COMMONS

\section{International Journal of Aviation,} Aeronautics, and Aerospace

\title{
Aerodynamic Design and Exploration of a Blended Wing Body Aircraft at Subsonic Speed
}

\author{
Sam Dakka Dr \\ The University of Nottingham, sam.dakka@tutanota.com \\ Oliver Johnson \\ Sheffield Hallam University, oliverjohnson@gmx.co.uk
}

Follow this and additional works at: https://commons.erau.edu/ijaaa

Part of the Aerodynamics and Fluid Mechanics Commons, and the Aeronautical Vehicles Commons

\section{Scholarly Commons Citation}

Dakka, S., \& Johnson, O. (2019). Aerodynamic Design and Exploration of a Blended Wing Body Aircraft at Subsonic Speed. International Journal of Aviation, Aeronautics, and Aerospace, 6(5). https://doi.org/ 10.15394/ijaaa.2019.1411

This Article is brought to you for free and open access by the Journals at Scholarly Commons. It has been accepted for inclusion in International Journal of Aviation, Aeronautics, and Aerospace by an authorized administrator of Scholarly Commons. For more information, please contact commons@erau.edu. 


\section{Aerodynamic Design and Exploration of a Blended Wing Body Aircraft at Subsonic Speed}

\section{Cover Page Footnote}

The research was self-funded. The authors would also like to thank ANSYS for the possibility to use their software. The research was conducted in the frame work of Oliver Johnson engineering degree in Aerospace Technology under the supervision and direction of Dr Sam M Dakka 


\section{Introduction}

The aviation industry has a long-term target set by the ICAO to reduce fuel burn and increase efficiency globally by $2 \%$ by 2050 (ICAO, 2010, 2016). Conventional aircraft efficiency has been improved dramatically over the last decade with new flow control systems such as; Wing lets and vortex generators, improving the aircraft efficiency further by reducing drag. Conventional aircraft improvement has seemed to plateaued and all changes made are making minute differences. Novel Concepts are now being analysed by companies such as Boeing, NASA, Airbus, and Lockheed Martin in an attempt to dramatically reduce drag caused by the aircraft and reach the ultra-sustainable status that is required from the ICAO and airlines. Blended wing body (BWB) aircraft is a novel concept which is a combination of a conventional tube and wing aircraft and a flying wing aircraft such as a Northrop Grumman B-2 Spirit stealth bomber. The wings and fuselage of a BWB are integrated to form one lifting body which gives it the name of blended wing body (BWB) (Allen, 2008; Leibeck, 2004). The BWB configuration is said that the wings, integrated to the larger and wider aerofoil centre body allows the entire aircraft to generate lift and reduce parasite drag, in particular interference drag (Leibeck, 2004; Qin et al., 2004). Due to a larger surface area of the aircraft exposed to producing lift, lift-induced drag increases. However, the improvements increase the overall lift to drag ratio providing a higher performance aircraft saving $27 \%$ fuel burn per passenger mile that of the modern conventional configuration (Allen, 2008; Leibeck, 2004). There are also many other positives outside of the aerodynamic improvements, these being; noise reduction, ease of manufacture, structural loading, MTOW reduction of $15 \%$, surface area reduction of $33 \%$ and benefits associated with in flight emergencies. All these benefits add to cost savings generating and operating the ultra-sustainable aircraft required by the ICAO. With efficiencies generated, airlines will then be able to look at longer flight paths or more affordable flights for customers which will expand the aviation industry in a positive manner.

\section{Blended Wing Body Programme}

\section{Research and Background Theory}

In 1998, NASA Langley Research centre began a long-haul aircraft design program after reviewing the potential market demand for long range aircraft. Shortly after, McDonnell Douglas started a preliminary design project looking at long haul transport focusing on the design and analysis of alterative aircraft configurations (Leibeck, 2004; Ordoukhanian \& Madni, 2014). The initial benefits captured from McDonnell Douglas was reduction in-flight fuel burn, reduced weight and significantly increase lift to drag ratio (Leibeck, 2004; Ordoukhanian \& Madni, 2014). It was this moment which gave NASA the incentive to fund further studies to critically compare conventional aircraft to this new blended configuration 
(Leibeck, 2004). NASA, along with McDonnell Douglas began an ambitious design program where the requirements were to design a subsonic aircraft (MACH 0.85 ) for 800 passengers and be able to travel to a range of 7000nm (Leibeck, 2004). The design went ahead as planned and was compared against a conventional tube and wing aircraft. The blended configuration concluded with a reduced maximum take-off weight of $15 \%$, reduced surface area of $33 \%$ and a reduction in fuel burn of $27 \%$ per passenger mile (Leibeck, 2004). Noise and emissions produced by the blended wing body was said to significantly reduce compared to conventional aircraft further reducing the operational cost of the blended configuration (Allen, 2008; Guo, Burley, \& Thomas, 2014; Leibeck, 2004; Ordoukhanian \& Madni, 2014). The only negative at this point was structural loading within the centre body. The blended wing body design continued to be evaluated, the design requirements changed slightly by reducing the passenger count to 468 passengers and increasing the range to $7750 \mathrm{~nm}$, this aircraft was called the BWB 450 (Ordoukhanian \& Madni, 2014). This design remained very similar but the aerodynamics was altered by Boeings software "WingMOD," the structural analysis was carried out by forms of finite element analysis and the propulsion was analysed using many different CFD techniques (Ordoukhanian \& Madni, 2014). Many additional positives were gained from this research such as; high performance at higher Mach speeds, ease of manufacture and the ability to perform well in emergencies (Ordoukhanian \& Madni, 2014). Recently, Boeing and NASA's Blended wing body (BWB) program, the BWB-X48B was designed to critically analyse the stability and on-board flight control systems, this was evaluated by carrying out flight tests using a manufactured scaled model and an indoor wind tunnel. With the first flight test taking place in June of 2007, 80 flights in total were carried out until the program finished in 2010, before the new BWB X-48C program began. Many lessons were learnt from the BWB X-48B program. One being what occurs to the BWB at $\alpha$ stall. When the BWB experiences a stall due to the aircraft being at a high angle of attack, the BWB enters a rotational tumble motion (Ordoukhanian \& Madni, 2014; Saephan \& Dam, 2008). For a BWB a rotational tumble is said to be extremely difficult if not impossible to exit due to the design of the BWB, this leads the BWB to fall until it crashes (Ordoukhanian \& Madni, 2014). In flight, this would be a catastrophic event meaning more analysis has to occur before planning to implement this configuration for commercial or military use. Boeing and NASA released a new program called the BWB X-48C where flight controls were added to prevent the BWB from stalling, further flight tests and wind tunnel tests were carried out until the program stopped in 2013. However, in 2016, (Boeing, 2016) NASA released a statement stating they're taking the BWB back to the wind tunnel for additional testing as they believe there is real scope for the blended wing configuration to be implemented into use as the new ultra-sustainable airliner. NASA is still keen to develop an ultra-sustainable aircraft which is why they have considered alternative 
blended designs on their NASA X-plane program. This program is designed to assist the development of many different novel concept aircraft which all show scope to increase efficiency (NASA, 2016). The NASA X-plane concepts range from blended wing configurations, quiet supersonic technology and electrically powered aircraft. Blended configuration projects on the NASA X-plane program are;

- $\quad$ Boeing's X-48 series BWB

- $\quad$ Lockheed martin Hybrid Wing body, which features with a conventional $\mathrm{T}$ tail empennage

- $\quad$ Aurora flight sciences D8 double bubble

- $\quad$ Dzyne Technologies ascent 1000 regional jet and BWB Biz Jet

From reviewing different projects, it has become apparent that NASA and Boeing have progressed the most and seem to lead the research and development of blended wing configurations, however other companies have seen the benefits blended configurations have to offer and have started to design their own ideas as displayed above. Despite the setbacks mentioned in the early programs, NASA and Boeing are still confident their BWB-48 series will be available commercially by 2030 (Boeing, 2013). Aurora flight sciences D8 double bubble concept is another contender for the 2030-2035 timescale, with a fuel burn reduction of $71 \%$ this aircraft could be the new market leader for blended designs if it sticks to the predicted timescale (Aurora, 2015). Dzyne Technologies regional jets are expected to enter service by 2025 (DZYNE, 2016). Lockheed martin has not released an inservice time scale suggesting they are still at preliminary design stages (LockheedMartin, 2014).

\section{Lift to drag characteristics.}

The $\mathrm{L} / \mathrm{D}$ ratio is the ratio between the Lift force and the Drag force associated to a particular aircraft. An aerodynamically efficient aircraft is deemed to have a High L/D ratio, this would suggest the aircraft generates a high amount of lift and low amount of drag (NASA, 2015). Many different factors affect the L/D ratio of a given aircraft, these being; Geometry design, area, aerofoil selection, wing positioning, wing sweep, trim, incidence angle and so on. Another study (Pang Jung Hoe, 2014) was carried out focusing on the L/D difference between BWB and conventional aircrafts. The models were tested at a cruise speed of 0.8 Mach and an approach speed of 0.16 Mach. The results of the study confirm that the BWB outperforms the conventional aircraft at both speeds, where at cruise there is a L/D improvement of $24 \%$ and at approach there is a L/D improvement of $23.79 \%$. Furthermore, the BWB does not consistently have higher lift and lower drag compared to the conventional aircraft to consist of a higher L/D ratio. This proves that the ratio between the Lift and drag is more important than aiming for one high parameter such as lift (NASA, 2015). Experimentally (Pang Jung Hoe, 2014), the 
optimal operational angle for this BWB design is between $\alpha-5^{\circ}$ to $\alpha 5^{\circ}$ with a suitable cruise angle of approximately $\alpha 5^{\circ}$ and a suitable approach angle of $1.5^{\circ}$ to $\alpha 2.5^{\circ}$.

In this particular experiment the maximum L/D is 8.5, which occurs at $\alpha 0^{\circ}$. However, the maximum L/D is not always desirable for a given airframe (Dehpanah \& Amir, 2015). The drag polar provides a relationship between the lift coefficient $(\mathrm{Cl})$ and drag coefficient $(\mathrm{Cd})$, the drag polar is used to determine the coefficient of drag the aircraft is encountering at a certain coefficient of lift. To find the maximum $\mathrm{Cl} / \mathrm{Cd}$ a tangent line is drawn from the origin to the curve (Dehpanah \& Amir, 2015). In this particular case, a $\mathrm{Cl}$ of approximately 0.175 experiences the least amount of drag which will provide the most efficient cruising condition. This is because from this point the gradient of the drag curve is extremely flat, meaning as the lift increases slightly, the drag will increase significantly, reducing the overall L/D (Pang Jung Hoe, 2014). The most efficient L/D is shown at Cl equal to 0.175. This analysis can provide other wing parameters, such as the type of aerofoil used and if the wing consists of an incidence angle. This particular case shows that the wing consists of cambered aerofoils and an incidence angle to generate such high lift at $\alpha 0^{\circ}$.

The conclusions based on reviewing the three different sources, there is a common ground for the desire of highest $\mathrm{L} / \mathrm{D}$ ratio possible to provide a foundation for the ultra-sustainable BWB. BWB performs best at low angles of attack $(\alpha)$ as shown by (Pang Jung Hoe, 2014) study suggesting $\alpha 5^{\circ}$ is the most optimum angle and study (Dehpanah \& Amir, 2015) showing $\alpha 0^{\circ}$ and (Peifeng, 2012) proving that $\alpha 2^{\circ}$ is the most optimal for their configuration. The ideal cruise angle has shown to be between $\alpha 0^{\circ}$ to $\alpha 5^{\circ}$ because with low $\alpha^{\circ}$ cruise angles, induced drag of the BWB can remain low whilst still generating high lift, it is these effects that give the BWB the required high $\mathrm{L} / \mathrm{D}$ ratio. However, there are many different parameters that cause the BWB to perform best at slightly different angles of attack such as; Wing positioning, Wing area, Wing span, Aspect ratio, aerofoil selection, wing sweep and incidence angle.

\section{Spanwise lift distribution.}

The thickness to chord ratio remains uniform across the span of BWB configuration. The coefficient of lift across the span of the BWB can be described by the Centre body experiences the highest $\mathrm{Cl}$ due to the aerofoil length and thickness at this point (Dehpanah \& Amir, 2015). The lift gradually reduces across the span to the wing tip where the geometry reduces. The lift distribution does not replicate a complete elliptical distribution suggesting there are still signs of induced drag associated with the BWB. However, reducing the connective gradient from centre body to the outboard wing will increase the chances of gaining an elliptical distribution.

The results of the lift distribution across one half of BWB was examined (Kanazaki et al. 2013). Two different runs were compared against the ideal 
elliptical distribution. Both runs experience spikes at approximately 30\%-40\% span, this point is where the centre body and outboard wing connect. Similarities between (Kanazaki et al. 2013) and (Dehpanah \& Amir, 2015) are seen at this area where the lift drops. The only way to increase lift at this area to generate an elliptical distribution is to make the connection between the center body and outer wing as smooth as possible (Dehpanah \& Amir, 2015; Kanazaki et al., 2013; Qin, Vavalle, \& Moigne, 2005).

An explanation of span-wise lift distribution, the thickness to chord ratio, and the $\mathrm{C}_{\mathrm{L}}$ distribution is needed. The thickness for subsonic flight is required to remain within 15\%-17\% (Liebeck, 2004). Larger geometries are selected for the centre body to contain cabin and systems. As lower lift is generated the further outboard you go, higher lifting aerofoils are required at this area. Selecting lower lift aerofoils for the inboard board will then balance the lift distribution. The drawback with this approach is that wing loading will be considerable on the outboard wing requiring greater reinforcements. Negative camber is added to the trailing edge center body aerofoils to balance trim (Liebeck, 2004). The design shows the lift distribution is elliptically distributed.

The comparison between conventional and BWB inertial load and aerodynamic lift reveals, the conventional aircraft shows that majority of inertial load comes from the fuselage, as the fuselage provides minimal lift, high stress on the connection between the fuselage and wing is seen. The BWB differs as lift is generated across the entire BWB reducing wing loading; this reduces structural requirements increasing structural efficiencies. Reducing the structural requirements reduces the aircraft weight. The balance and stability of the BWB changes as more lift is provided centrally, this changes the force dynamics than that of conventional which is why stability is preventing BWB being commercially deployed (Okonkwo \& Smith, 2016).

\section{Surface pressure distribution.}

The pressure coefficient across the chord of the BWB at different span locations was evaluated. A high positive pressure is experienced at the leading edge of the BWB, this is known as the stagnation point where the flow first comes in contact with the BWB. The high negative pressure on the upper surface suggests the velocity is traveling faster over the top surface than it is over the bottom surface, high suction occurs due to the pressure differences meaning lift is generated. The thickness of the aerofoil directly correlates with the Cp graph where the flow over the Centre body $(10 \%, 20 \%)$ starts to separate earlier on than that of the outboard sections (Kroo, 2005). The outboard aerofoil thicknesses are reduced meaning the flow stays attached for longer; this can be seen in the outboard Cp Graphs (Dehpanah \& Amir, 2015). The Cp graphs shows that the flow over the bottom surface remains relatively uniform at all chordwise locations. 
The BWB pressure distribution over the upper and lower surface can be described as follows (Kanazaki et al., 2013). The upper surface of the Centre body shows that the pressure remains at relatively low negative value where it gradually increases just before the trailing edge where the flow starts to separate. The negative pressure is seen towards the merging point. This point is where both the centre body and outboard wing connects; the sudden change in geometry causes the velocity to increase. The pressure is seen at its highest negative value at the leading edge of the outboard wing from the merging point until the span; this is expected from basic sweep theory (Revolvy, 2016). The thickness to chord ratio of the outer wing is minimal therefore the flow remains attached for longer than it does at the centre body.

Final blended wing body geometry design.

The design methodology proposed by Kanazaki et al., 2013, will be adhered for validation. This methodology offsets different aerofoil sections in the spanwise location as a percentage of the total span and then lofts them together in Solidworks. The same method is applied when setting the aerofoils in the chordwise locations. The chords can be set as a percentage of the centreline chord or can be set by using a Bezier curve. For simplicity, the chord wise locations will be set as a percentage of the centreline chord. The specific chord lengths are not specified when sizing them as a percentage of the largest chord. Meaning it is down to the designer to choose appropriate chord lengths.

\section{Geometry design.}

Inboard centre body.

The Inboard centre body, as per the product design specification is designed with a symmetrical NACA 0012 aerofoil. The NACA 0012 aerofoil was selected as it is designed for subsonic speeds, consists of a high $\alpha$ stall angle. The positives for a high lifting aerofoil with a high $\alpha$-stall means that the stalling process will not occur easily and can allow testing to occur over a large range of $\alpha^{0}$ as well as the pilot to be able to carry out high $\alpha$-stall manoeuvres in emergencies. If a cambered aerofoil such as a NACA 6 series was selected, a limitation to angle of attacks between $\alpha 5^{\circ}-\alpha 10^{\circ}$, this leaves minimal room for pilot error and emergencies, raising the risk of catastrophic rotational tumbling when BWB's stall. As shown in Figure 1 the centre body is made up of 3 aerofoil sections located at $0 \%$ span, $15 \%$ span and $30 \%$ span, the datum being the nose aerofoil of the centre body $(0 \%$ spanwise and $0 \%$ chordwise location). The aerofoils are then positioned in the chordwise location $0 \%, 16 \%$ and $38 \%$. The centre body consists of $0^{\circ}$ incidence angle. 


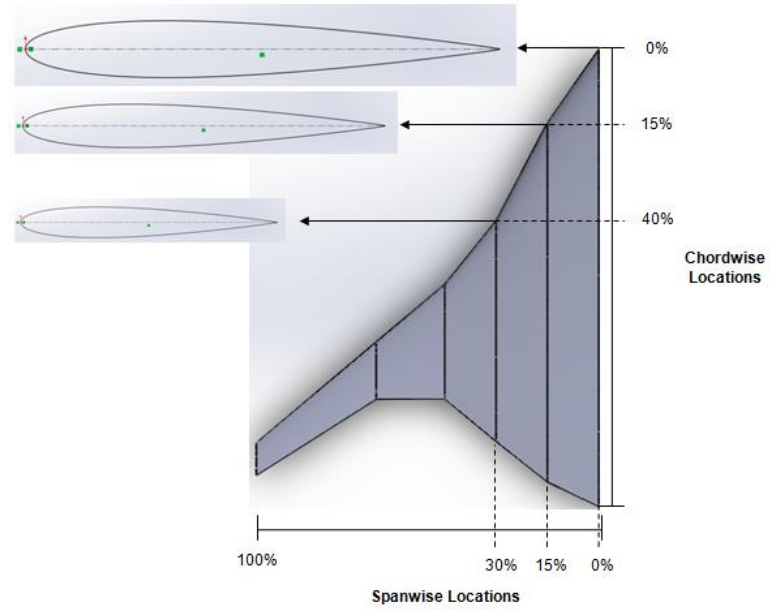

Figure 1. Inboard center body design.

\section{Outboard wing.}

The outboard wing also consists of a NACA 0012 aerofoil for simplicity and the same reasons mentioned above. The NACA 0012 aerofoil allows the 10th scale model adequate thickness to consist of internal pressure taps for testing. Using 3 aerofoils for the outboard wing, the first is set at $45 \%$ span, the second at $65 \%$ span and the final aerofoil set at $100 \%$ span. The chordwise length and position of the model (Kanazaki et al, 2013) is not specified, therefore the chord length and position were selected to achieve a sweep angle of $40^{\circ}$ as this produces the highest L/D according to (Siouris \& Qin, 2007) for BWBs. The chordwise positioning of the outer wing was $50 \%, 65 \%$ and $85 \%$ of the chord as shown in Figure 2. 


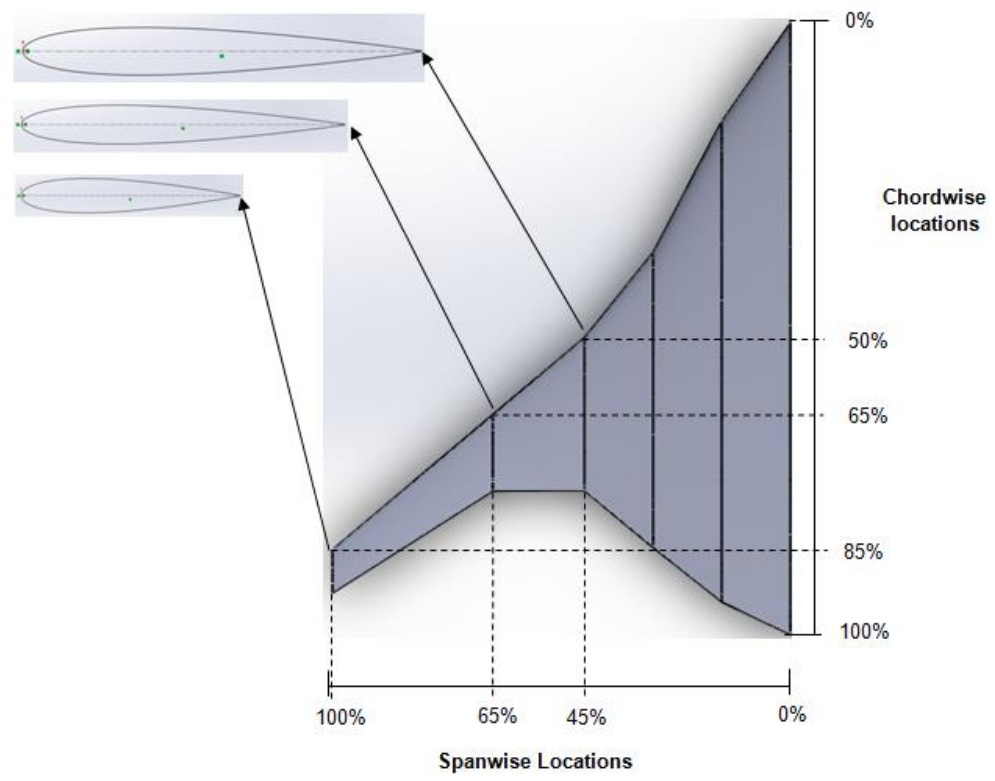

Figure 2. Outboard center body design.

Incidence angles were added from $45 \%$ span to $100 \%$ span to maximize lift generated on the outboard wing to encourage elliptical spanwise lift distribution, reducing induced drag (Leibeck, 2004; Ordoukhanian \& Madni, 2014; Qin et al., 2005). The $45 \%$ span aerofoil consists of an incidence angle of $0.75^{\circ}, 65 \%$ span consists of an incidence angle of $1.5^{\circ}$ and $100 \%$ span consists of an incidence angle of $2^{\circ}$, as shown in Figure 3. Each aerofoil profile was positioned into Solidworks and lofted to integrate the inboard centre body to the outer wing to generate the BWB.

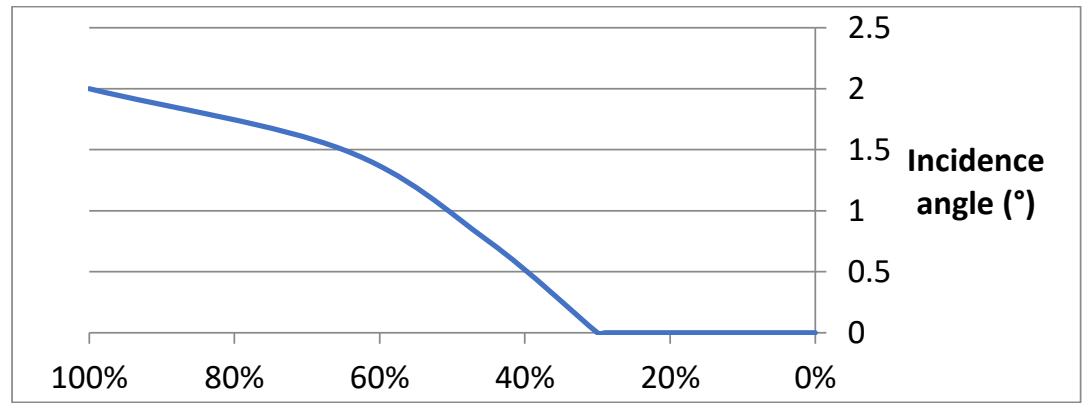

Figure 3. Aerofoil span incidence angle. 


\section{Computational fluid dynamics.}

\section{CFD methodology.}

The following conditions were used to simulate the blended wing body in Ansys fluent. The idea of CFD is to get an understanding of how the BWB behaves in set conditions before the manufacturing and testing stages. This method increases cost savings and reduce time taken to get a valid data set. The CFD simulations will be set to the same conditions that will be experienced by the subsonic Wind tunnel to increase the likelihood of generating valid data. The simulations will then be compared with the results gained from the wind tunnel testing. Once this first comparison has occurred, higher speeds can be analysed.

\section{Geometry domain.}

The BWB body has a maximum chord length of $280 \mathrm{~mm}$ and a semi span of $210.15 \mathrm{~mm}$. The Length of the domain in the wake from the nose datum is $2800 \mathrm{~mm}$. The $\mathrm{C}$ shaped inlet has a radius of $1000 \mathrm{~mm}$ and is extruded $90^{\circ}$ as shown in Figure 4 , this means that the geometry domain for the BWB is 3.5 lengths upstream and 9 body lengths downstream using the nose of the BWB as the datum. This is sufficient according to Ansys (2016).

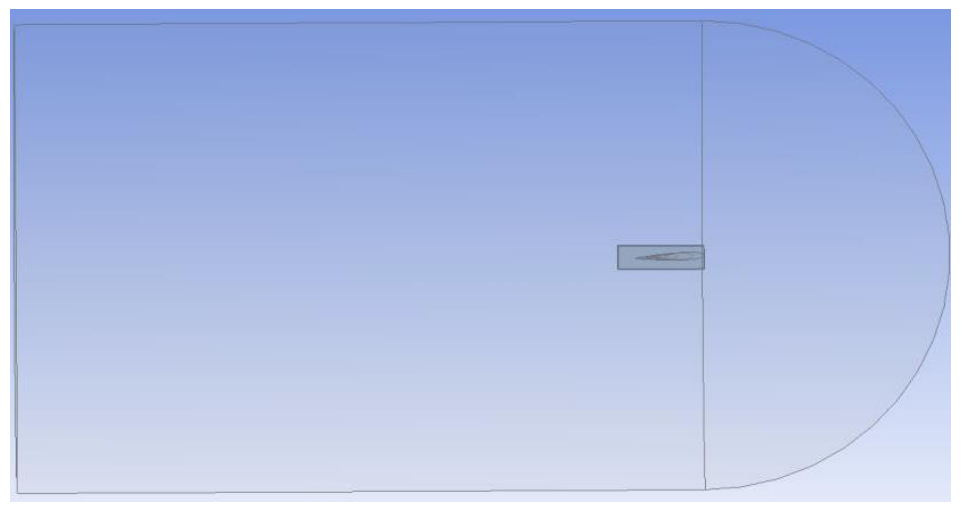

Figure 4. C shaped domain.

Figure 5 shows the plan view of the BWB with a body of influence in the $\mathrm{C}$ shaped domain. 


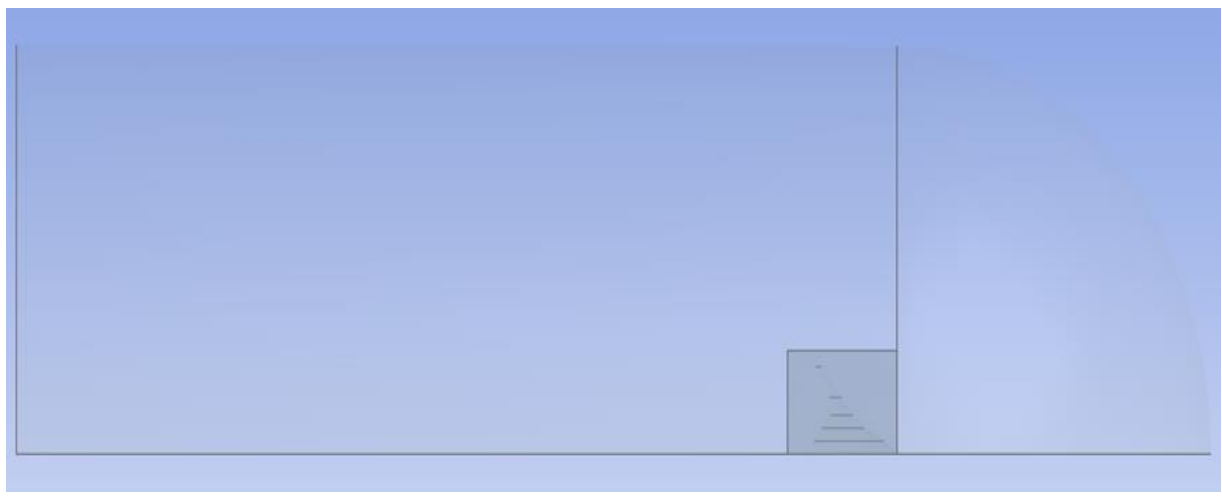

Figure 5. Plan view of the geometry domain

\section{Meshing.}

Over 20 different simulations occurred; each mesh differs slightly due to the primitive box position and the size of the box due to the different angle of attacks tested. Although the domain, mesh sizing and refinements were kept exactly the same, the element count varied slightly across each simulation. As the meshes for all simulations were set up the same way they are all very similar. Below is an example mesh which each simulation was based from.

\section{Sizing.}

Table 1 illustrates average meshing characteristics and Figure 6 shows the BWB mesh after the mesh sizing's were applied. For simplicity and time efficiency for solving the physics equations the following mesh sizing was used;

- $\quad$ Size Function: Proximity and Curvature

- $\quad$ Min size: $0.5 \mathrm{~mm}$

- $\quad$ Proximity Min size: $0.5 \mathrm{~mm}$

- Max Face Size: $400 \mathrm{~mm}$

- $\quad$ Max Tet Size: $400 \mathrm{~mm}$

- $\quad$ Growth Rate: 1.2

Table 1

Averaged Mesh Characteristics

\begin{tabular}{llllll}
\hline $\begin{array}{l}\text { Orthogonal } \\
\text { Quality }\end{array}$ & Skewness & $\begin{array}{l}\text { Aspect } \\
\text { ratio }\end{array}$ & $\begin{array}{l}\text { Yplus } \\
\text { Value }\end{array}$ & Elements & $\begin{array}{l}\text { Refinements } \\
\text { to mesh }\end{array}$ \\
\hline 0.86 & 0.22 & 1.8 & $30-300$ & 1271159 & $\begin{array}{l}2 \text { layer } \\
\text { Inflation/ } \\
\text { Body of } \\
\text { influence }\end{array}$ \\
\hline
\end{tabular}




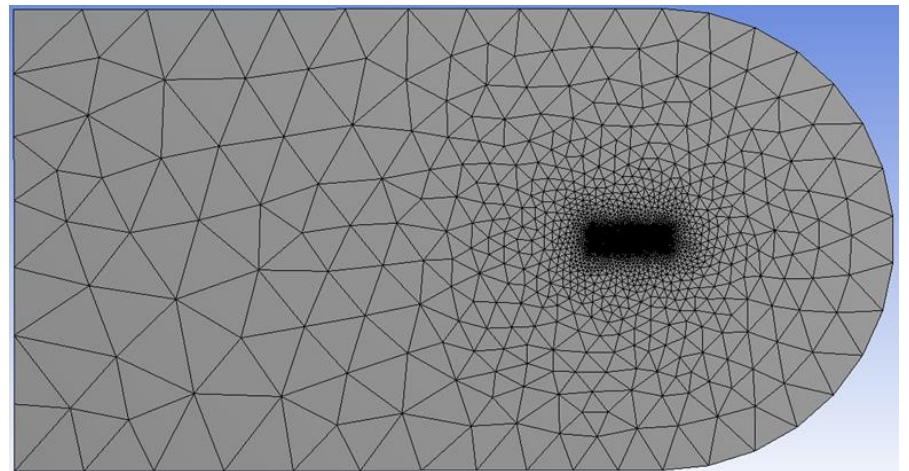

Figure 6. BWB mesh sizing including a body of influence

\section{Refinements.}

Refinements are added to satisfy the $\mathrm{Y}$ plus values, skewness and orthogonal quality as shown below (ANSYS, 2009, 2015; Thakar \& Upadhyay, 2015).

\section{Body of influence.}

Body of influence is used to refine the mesh density around the area of importance. This enables the area around the aerofoil to be extremely refined to increase the accuracy of the physics calculations which provides a more realistic understanding of what happens to the BWB in set conditions (ANSYS, 2009). The BWB consists of complex trailing edge geometry around the outboard wing which means a body of influence is an appropriate choice of refinement (ANSYS, 2015).

Figure 7 shows the body of influence, as previously described; you can see how the mesh density has increased around the BWB. Outside of the body of influence the refinement is not so important therefore it is acceptable to reduce cell quantity, increasing the cell size reduces the cell quantity meaning there are less calculations to take place, this then reduces the time taken for the program to solve the physics.

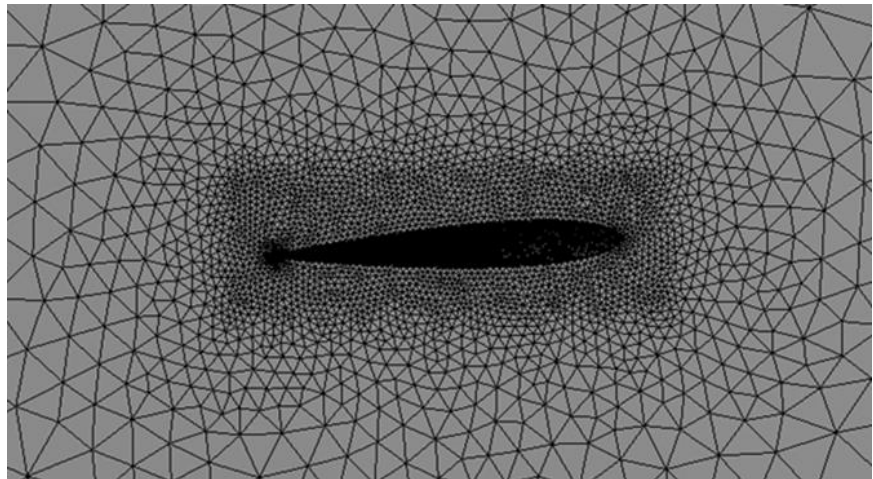

Figure 7. Body of influence used for the BWB simulation. 


\section{Inflation.}

Figure 8 shows the inflation around the aerofoil, the inflation is used to generate a high-quality mesh around the wall of the aerofoil to capture the flow behaviour around the boundary layer. The inflation is required to satisfy the $\mathrm{Y}$ plus value which determines the ideal distance from the wall (aerofoil surface) to the first mesh cell. Dependent on the turbulence model selected the distance of the first cell to the aerofoil (wall) varies. The model used in this study is K-epsilon non equilibrium wall functions meaning the $\mathrm{Y}$ plus value can be between; 30-300. Y plus of 100 is selected meaning the total thickness of the 2-layer inflation is $2 \mathrm{~mm}$, the first layer is positioned at $1 \mathrm{~mm}$ to satisfy the Y plus.

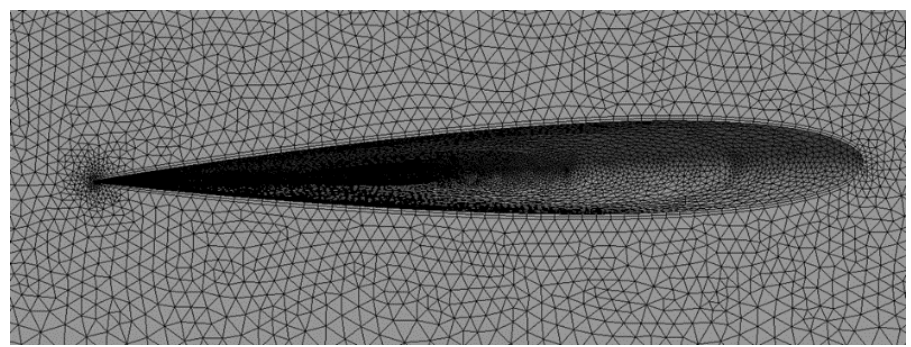

Figure 8. Layer boundary layer inflation

Figure 9 shows a wireframe view of the mesh around the BWB. The mesh is refined around the leading and trailing edge of the BWB, the cells increase around the complex geometry as seen by the outboard wing. With a mesh skewness value average of 0.22 , orthogonal quality average of 0.86 , this is a good mesh for the intended application meaning it is ready for fluent (ANSYS, 2006, 2015, 2016).

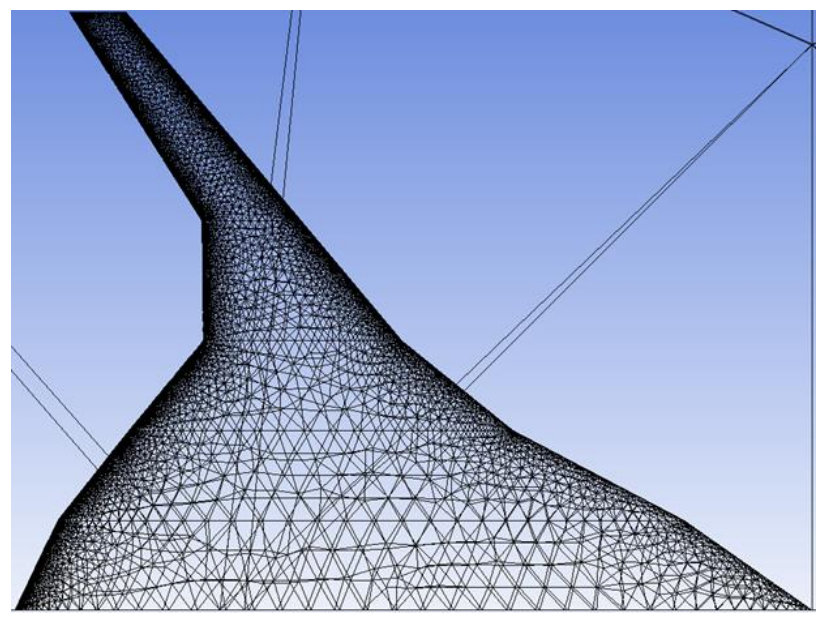

Figure 9. Wireframe mesh view to analyze mesh refinements over the BWB. 


\section{Fluent.}

Table 2 illustrates CFD simulation conditions.

Table 2

Fluent Set-up

\begin{tabular}{|c|c|c|c|c|c|}
\hline $\begin{array}{c}\text { Velocity } \\
(\mathrm{m} / \mathrm{s})\end{array}$ & $\begin{array}{l}\text { Temperature } \\
\text { (K) }\end{array}$ & $\begin{array}{l}\text { Air } \\
\text { density } \\
\left(\mathrm{kg} / \mathrm{m}^{3}\right)\end{array}$ & $\begin{array}{l}\text { AOA } \alpha^{\circ} \\
\text { (increments } \\
\text { of } 5^{\circ} \text { ) }\end{array}$ & $\begin{array}{l}\text { Model } \\
\text { (Turbulent) }\end{array}$ & $\begin{array}{l}\text { Wall } \\
\text { Function }\end{array}$ \\
\hline 25 & 294.15 & 1.225 & $-20^{\circ}$ to $+20^{\circ}$ & K-epsilon & $\begin{array}{l}\text { Non- } \\
\text { Equilibrium } \\
\text { Wall } \\
\text { Function }\end{array}$ \\
\hline 60 & 294.15 & 1.225 & $-20^{\circ}$ to $+20^{\circ}$ & K-epsilon & $\begin{array}{l}\text { Non- } \\
\text { Equilibrium } \\
\text { Wall } \\
\text { Function }\end{array}$ \\
\hline
\end{tabular}

\section{CFD Simulation Results}

Coefficient of lift and Drag.

Figure 10a shows the Lift Coefficient over $\alpha^{0}$ for both $25 \mathrm{~m} / \mathrm{s}$ and $60 \mathrm{~m} / \mathrm{s}$. The maximum $\mathrm{Cl}$ for both speeds occurs at $\alpha 20^{\circ}$. The Maximum $\mathrm{Cl}$ for $25 \mathrm{~m} / \mathrm{s}$ is $\mathrm{Cl} 0.807$ and the maximum at $60 \mathrm{~m} / \mathrm{s}$ is $\mathrm{Cl} 0.728$. As the angle of attack increases, the lift at both speeds' increases. It is worth noting the Figure shows no signs of stall, however, $60 \mathrm{~m} / \mathrm{s}$ at $\alpha 20^{\circ}$ the Lift starts to drop, this suggests that at $\alpha 25^{\circ}-$ $\alpha 30^{\circ}$ the BWB may encounter stall. The $\mathrm{Cl}$ over $\alpha^{\mathrm{o}}$ for both speeds is very similar with minimal difference up until $\alpha 10^{\circ}$, where $60 \mathrm{~m} / \mathrm{s}$ encounters a slight drop, this could be due to mesh differences. Figure $10 \mathrm{~b}$ shows the coefficient of drag over $\alpha^{\mathrm{o}}$. The Coefficient of drag remains very low between $\alpha-5^{\circ}-\alpha 5^{\circ}$, optimal operation conditions would occur between these angles to maintain high efficiency during flight. The same characteristics were seen in other BWB studies (Dehpanah \& Amir, 2015; Pang Jung Hoe, 2014; Kanazaki et al., 2013) which suggests the simulations carried out are credible. The Cd remains low between $\alpha-5^{\circ}-\alpha 5^{\circ}$ because there is less area exposed to generate lift causing the induced drag to reduce significantly. From observing the $\mathrm{Cd} / \alpha$ graph, at $60 \mathrm{~m} / \mathrm{s}$ the curve appears to lie just below the $25 \mathrm{~m} / \mathrm{s}$ curve suggesting that the BWB generates less drag at $60 \mathrm{~m} / \mathrm{s}$. This information provides data to confirm the BWB is more efficient at higher speeds. 


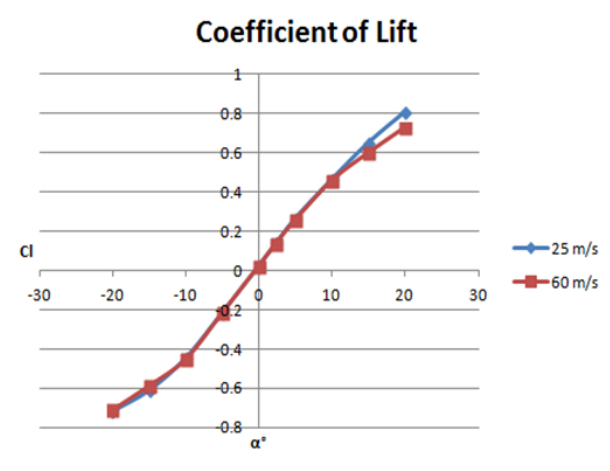

(a)

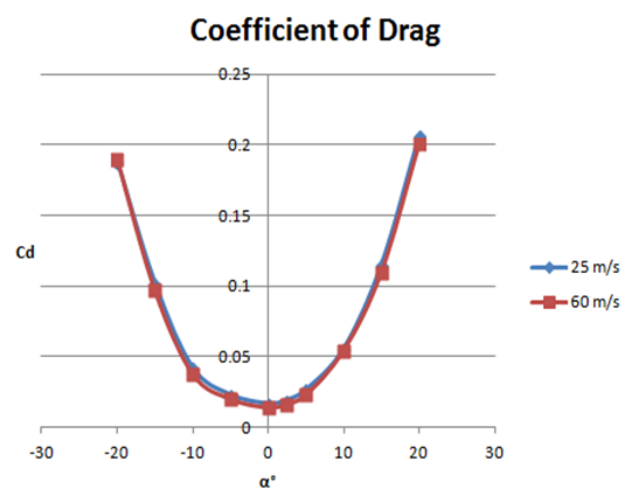

(b)

Figure 10. (a) CFD Coefficient of Lift versus angle of attack; (b) CFD Coefficient of Lift versus angle of attack at $25 \mathrm{~m} / \mathrm{s}$ and $60 \mathrm{~m} / \mathrm{s}$.

\section{Lift and drag charcteristics.}

The Drag polar graph displayed in Figure 11 displays the $\mathrm{CFD} \mathrm{Cl/Cd}$ results at $25 \mathrm{~m} / \mathrm{s}$ and $60 \mathrm{~m} / \mathrm{s}$. The relationship shows that during high lift coefficients the drag significantly increases for both speeds. Drawing the tangent line from the origin provides a $\mathrm{Cl} / \mathrm{Cd} \max$, the $\mathrm{Cl} / \mathrm{Cd} \max$ is gained at medium to low lift coefficients where the drag is considerably reduced. At $60 \mathrm{~m} / \mathrm{s}$ provides less drag than $25 \mathrm{~m} / \mathrm{s}$ as shown by the drag polar graph. At $\mathrm{Cl}-0.2$ to $\mathrm{Cl}+0.2$ the $\mathrm{BWB}$ experiences minimal drag, beyond this point the drag increases significantly as the lift increases slightly. The lift to drag ratio shown in Figure 11 compares the L/D Ratio over AOA $(\alpha)$ for both $25 \mathrm{~m} / \mathrm{s}$ and $60 \mathrm{~m} / \mathrm{s}$. At $25 \mathrm{~m} / \mathrm{s}$ the maximum L/D is 10 , this is obtained at $\alpha 5^{\circ}$. Setting the cruise angle at $\alpha 5^{\circ}$ is the most efficient condition the BWB can obtain whilst at $25 \mathrm{~m} / \mathrm{s}$ and $60 \mathrm{~m} / \mathrm{s}$. looking at $60 \mathrm{~m} / \mathrm{s}$ the $\mathrm{L} / \mathrm{D}$ is greater in both the positive and negative $\alpha$ angles. The BWB at $60 \mathrm{~m} / \mathrm{s}$ has a maximum L/D ratio of 11.0895 which is a $9.8 \%$ increase from $25 \mathrm{~m} / \mathrm{s}$. This suggests that the BWB is approximately $10 \%$ more efficient at higher speeds. Both simulation results follow the same trend on the graph; this provides certainty that the results are accurate and meaningful. 


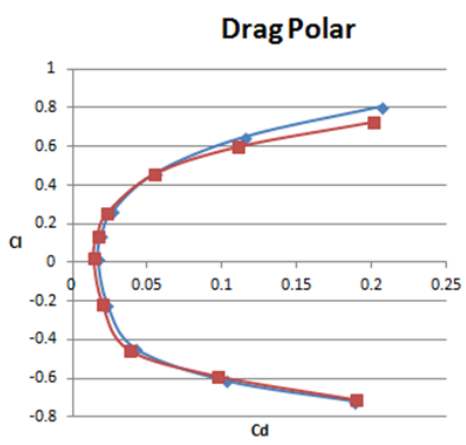

(a)

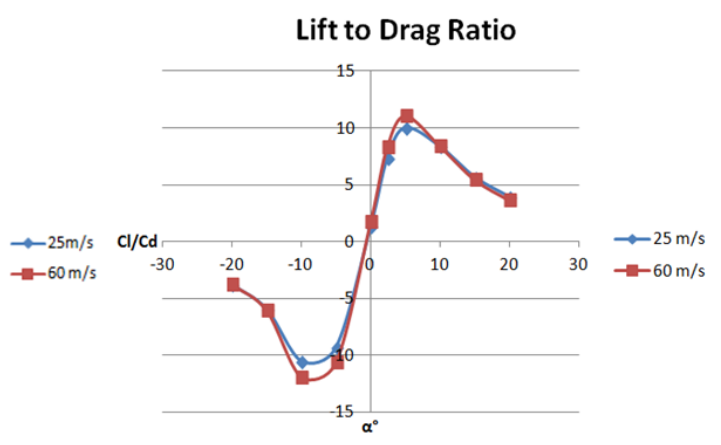

(b)

Figure 11. (a) CFD Drag Polar at $25 \mathrm{~m} / \mathrm{s}$ and $60 \mathrm{~m} / \mathrm{s}$; (b) CFD Lift to Drag ratio Coefficient at $25 \mathrm{~m} / \mathrm{s}$ and $60 \mathrm{~m} / \mathrm{s}$.

\section{Surface Pressure Distribution \\ Coefficient of Pressure Distribution $25 \mathrm{~m} / \mathrm{s} \alpha 2.38^{\circ}$}

Figure 12 shows contours of pressure coefficient across the upper and lower surface of the BWB at $2.38^{\circ} 25 \mathrm{~m} / \mathrm{s}$. The nose of the blended wing body is experiencing the highest amount of pressure, this is known as total pressure or the stagnation point, this is expected and displayed by red contours in Figure 12 where the stagnation point (large positive value) at $0 \%$ span and at each aerofoil section is observed. At $0 \%$ span the frontal pressure is at its largest due to the thickness and area of the BWB nose compared to the smaller aerofoil sections across the span of the BWB, this behaviour is replicated across all aerofoil sections as shown in Figure 12. Contours of pressure coefficient in Figure 12, shows the upper surface of the BWB has very high negative pressure compared to the lower surface. High negative pressure means the air is travelling at a high velocity, meaning the velocity over the top surface is higher than it is over the lower surface generating suction. Suction provides the BWB with lift. This is expected as shown by previous studies (Dehpanah \& Armir, 2015; Kanazaki et al., 2013; Kuntawala, 2011; Pang Jung Hoe, 2014). The flow over the outboard wing aerofoils (span 45\%,65\% and 100\%) remains attached to the boundary for longer, where signs of separation just before the trailing edge are observed, although signs of separation occurs it is still minimal showing minimal signs of vortex drag. The highest velocity is experienced at the leading edge of $65 \%$ span where the centre body and outboard wing connect; this can be seen on Figure 12 as blue contours. The pressure remains negative along the leading edge until the wing tip as expected from basic sweep theory (Revolvy, 2016). Again, this behaviour was also seen in previous studies (Dehpanah \& Armir, 2015; Kanazaki et al., 2013; Kuntawala, 2011; Pang Jung Hoe, 2014) suggesting the work carried out is valid. 


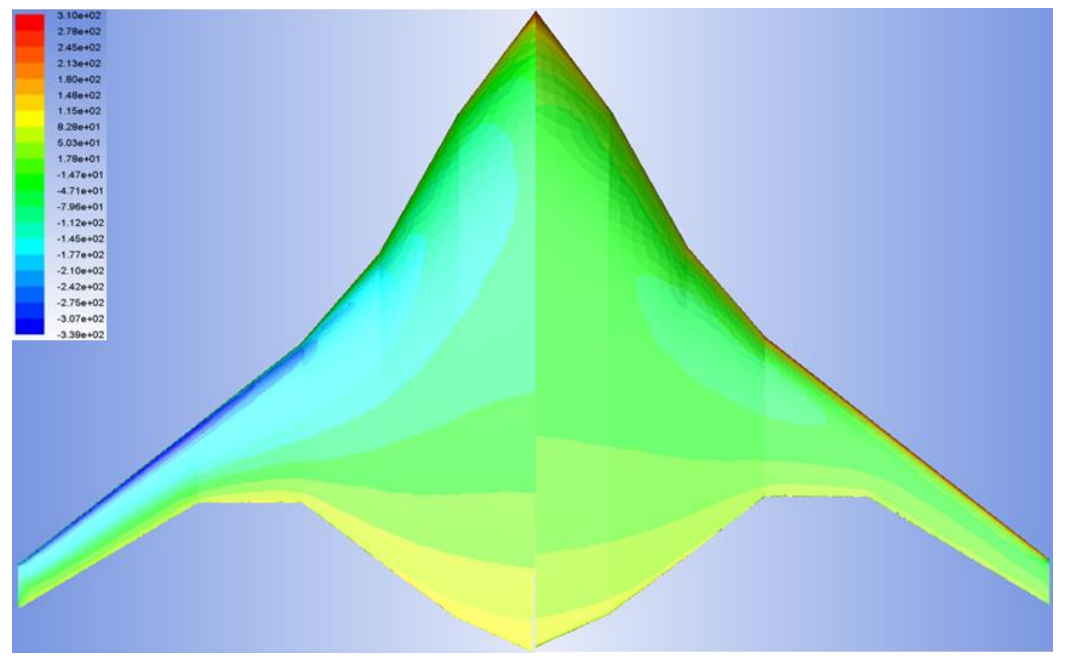

Figure 12. BWB upper and lower surface coefficient of pressure distribution at $\alpha 2.38^{\circ} 25 \mathrm{~m} / \mathrm{s}$.

Looking at the upper surface of the inboard centre body in Figure 12, the flow remains attached across the BWB up until approximately $85 \%$ of the centreline chord, it is at this point where the pressure positively increases (yellow contours) and eventually show signs of separation just before the trailing edge at around $200 \mathrm{~mm}$ chord. By getting further outboard, the aerofoil chord and profile thickness reduces, this is why the flow remains attached over the aerofoil profiles for longer than it does over the inboard profiles. The pressure across the lower surface of the BWB remains relatively uniform. Between $30 \%$ and $45 \%$ span there is a sudden increase in negative pressure, this is subject to the sudden geometry as previously mentioned (Leibeck, 2004). The flow remains attached across the majority of the chord and then experiences a slight increase in pressure, from this point the pressure gradually increases until it reaches the trailing edge where the flow starts to separate. At $100 \%$ span in Figure 12 shows the flow remains attached up until the tip of the trailing edge which is the ideal behaviour to be seen (Revolvy, 2016).

\section{Coefficient of Pressure Distribution $60 \mathrm{~m} / \mathrm{s} \alpha 2.38^{\circ}$}

Figure 13 shows the pressure contours at $\alpha 2.38^{\circ}$ at $60 \mathrm{~m} / \mathrm{s}$. The pressure distribution behaves the same way as it does at $\alpha 2.38^{\circ}$ at $25 \mathrm{~m} / \mathrm{s}$ with minimal differences. $60 \mathrm{~m} / \mathrm{s}$ will experience higher static pressure in Pascal's but when converted to the non dimensionless coefficient the behaviour is almost identical. However, the pressure over the upper surface of the $60 \mathrm{~m} / \mathrm{s}$ test shows that the flow remains attached for slightly longer than it does at $25 \mathrm{~m} / \mathrm{s}$. This 
immediately suggests that the onset of separation is delayed reducing the vortex drag associated with the BWB. Reducing the induced drag will reduce the overall coefficient of drag improving the L/D ratio as seen in experimental section. At $100 \%$ span shows a strong adverse pressure gradient, increasing the likely hood of stall compared to the inboard aerofoil sections this is ideal and expected due to the incidence angle of $2^{\circ}$ on the wing tip (Leibeck, 2004; Ordoukhanian \& Madni, 2014; Qin et al. 2005).

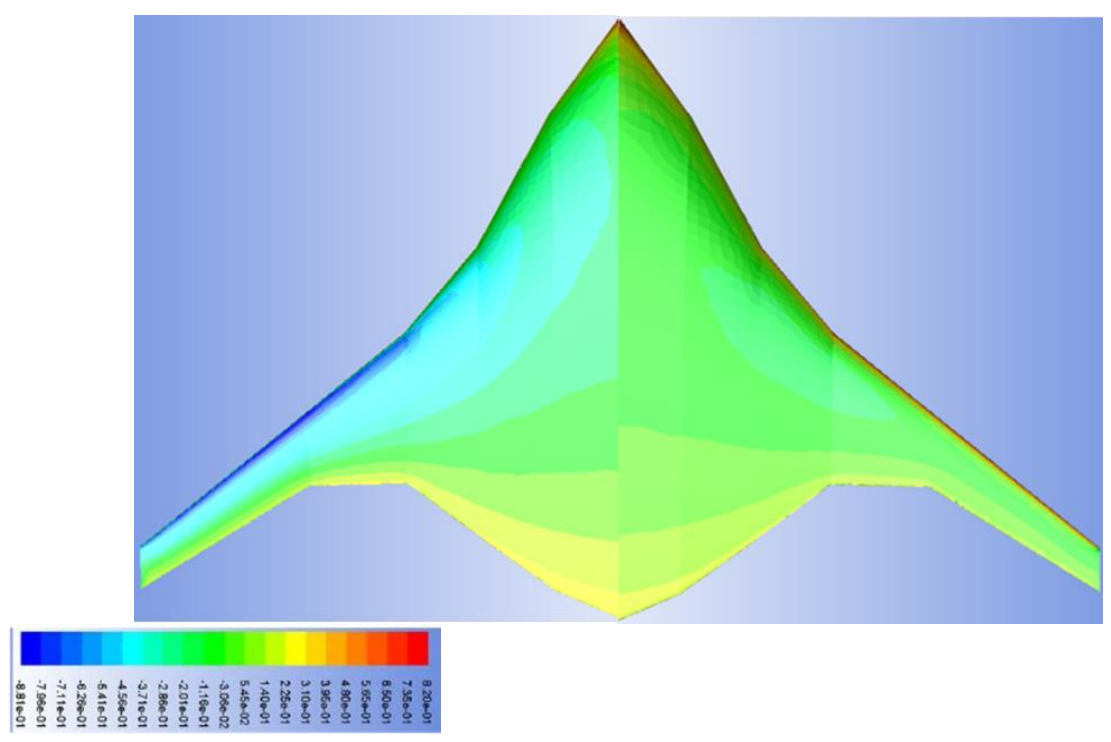

Figure 13. BWB upper and lower surface coefficient of pressure distribution at $\alpha 2.38^{\circ} 60 \mathrm{~m} / \mathrm{s}$.

\section{Spanwise lift distribution.}

Based on Kanazaki et al.'s previous study which multiplies the total $\mathrm{Cl}$ by the chord lengths at different spanwise locations to get a spanwise distribution graph, the graph is used to observe wing loading across the span. The ideal graph would be an elliptically distributed; this is to keep the induced drag as low as possible for that given geometry. As shown in Figure 14. The same approach described above (Kanazaki et al., 2013) has been used to display the lift distribution across the span. As expected, the inboard area provides the highest lift where it rapidly declines to the trailing edge as the aerofoil sections reduce in size and length. This is a poor span wise lift distribution as the lift between $20 \%$ and $60 \%$ span is extremely low, the way to improve this distribution is to increase the geometry in the span wise direction (20\%-60\%) and positioning at these locations. 


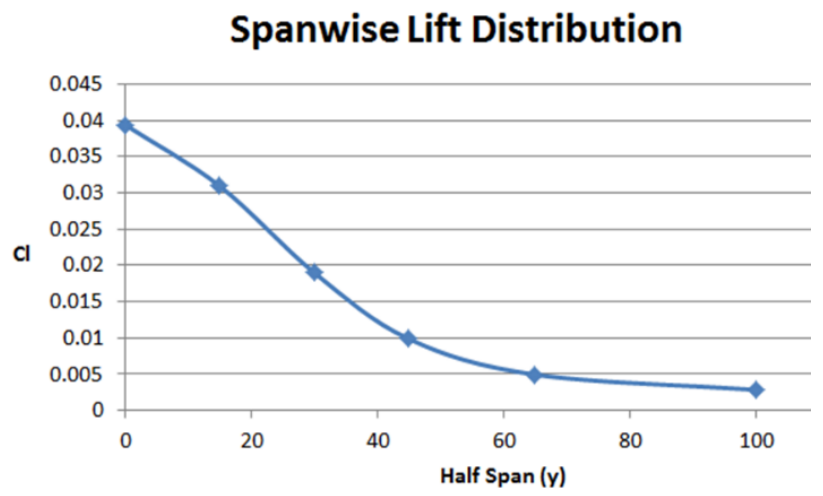

Figure 14. Spanwise lift distribution of the BWB.

\section{High speed analysis-lift to drag characteristics.}

Figure 15 shows comparison of the coefficient of lift, coefficient of drag, drag polar and the lift to drag ratio of the BWB at Mach 0.6. The image shows the results at MACH 0.6 compared $25 \mathrm{~m} / \mathrm{s}$ and $60 \mathrm{~m} / \mathrm{s}$. The coefficient of lift at Mach 0.6 increases by an average of $1.6 \%$ across all $\alpha^{\circ}$ as compared to $60 \mathrm{~m} / \mathrm{s}$. The lift coefficient at Mach 0.6 increases by an average of $2.5 \%$ across all $\alpha^{\circ}$ as compared to the lift coefficient at $25 \mathrm{~m} / \mathrm{s}$. This suggests that the higher the speed the greater the lift that is generated. Looking at the drag coefficient graph in Figure 15, Mach 0.6 is below both $25 \mathrm{~m} / \mathrm{s}$ and $60 \mathrm{~m} / \mathrm{s}$ tests suggesting the drag is reduced at Mach 0.6. Looking at the raw data the drag is reduced across all $\alpha^{\circ}$ by an average of $12.6 \%$. At $\alpha-5^{\circ}$ to $\alpha 5^{\circ}$ the drag reduction at each angle $\alpha^{\circ}$ is averaged to $21.8 \%$ which is a considerable reduction. The greatest reduction of drag is seen at $\alpha 0^{\circ}$ where there is a $28.9 \%$ reduction in drag. The Drag polar is very similar at Mach 0.6 than it is at slower speeds, where between $\mathrm{Cl}-0.25$ and $\mathrm{Cl} 0.25$ the drag remains low, beyond these limits the drag increases dramatically with the shallow drag gradient. The lift to drag ratio shows that at Mach 0.6 the BWB provides the greater $\mathrm{L} / \mathrm{D}$ ratio than it does at $25 \mathrm{~m} / \mathrm{s}$ and $60 \mathrm{~m} / \mathrm{s}$. With an averaged L/D improvement of $11.4 \%$ over all $\alpha^{\circ}$ angles, the BWB is more efficient at higher speeds than it is a lower speed. The maximum L/D at Mach 0.6 increases by $21 \%$ from $25 \mathrm{~m} / \mathrm{s}$ and increases by $12.8 \%$ from $60 \mathrm{~m} / \mathrm{s}$, both increases seen at $\alpha 5^{\circ}$. From the results discussed, this suggests that the optimal cruise condition for this BWB is at $35,000 \mathrm{ft}$, Mach 0.6 and at an angle of attack between $\alpha 2.38^{\circ}$ and $\alpha 5^{\circ}$. 

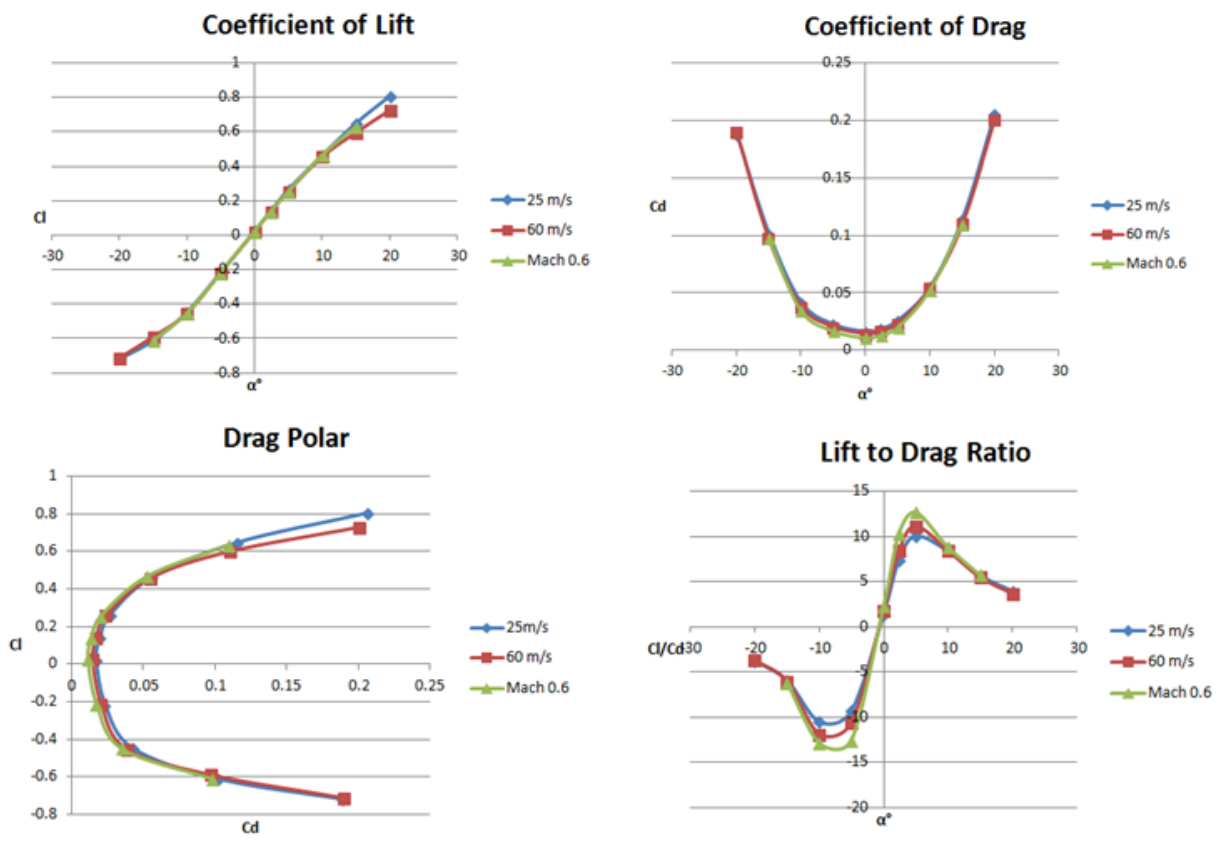

Figure 15. Low subsonic speeds Vs MACH 0.6 for coefficient of Lift, Drag, Drag Polar, and L/D.

\section{Blended Wing Body Manufacture}

Using the same BWB CFD model, it is then possible to design additional features to incorporate into the prototype to be manufactured for testing. Designing for manufacture is carried out to ensure the process of manufacturing occurs at ease and to be certain that the model will appear as required once manufactured, so the relevant testing can occur. Figure16 illustrates the final BWB manufactured model and the final BWB installed in the wind tunnel. 


\section{Final Test Piece}

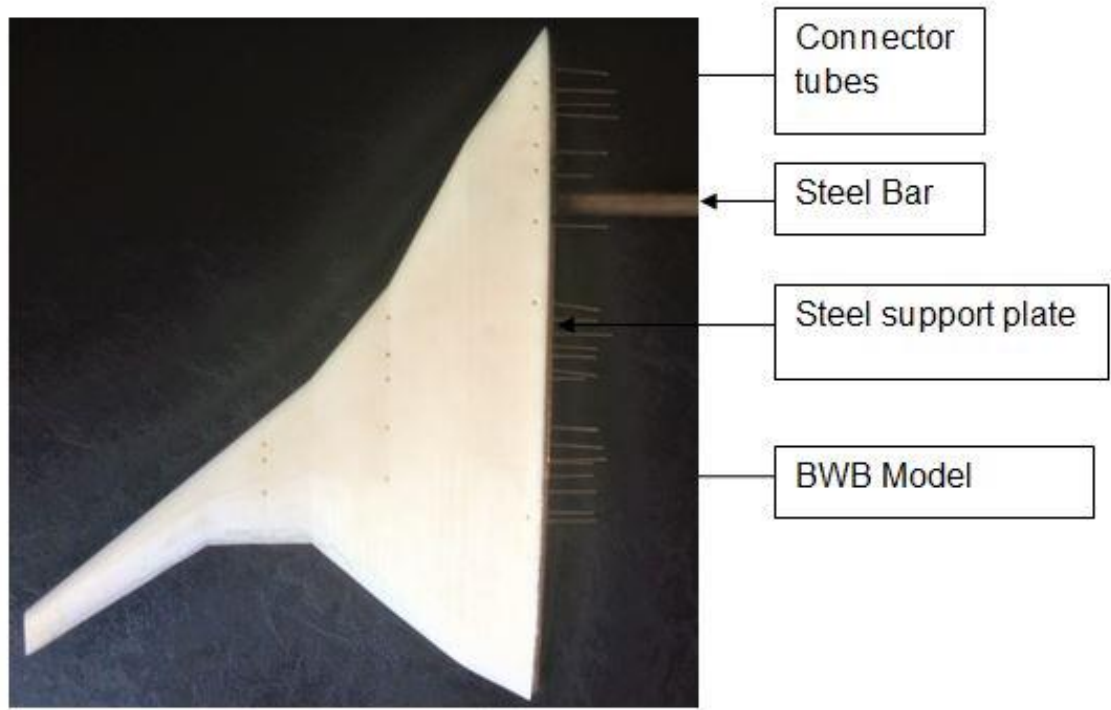

Figure 16. The final BWB manufactured model and the final BWB installed in the wind tunnel.

\section{Introduction}

\section{Wind Tunnel Testing}

Wind tunnel testing is carried out to ensure that a model being physically submerged into set conditions behaves the same as it does in simulation. Therefore, wind tunnel data can be used to validate simulations as well as to provide a greater data set around the topic that is being investigated to ensure work is credible and reliable. The subsonic Wind tunnel in this case is being used to validate simulations and back up the investigation around blended wing bodied aircraft at low subsonic speeds. Figure17 illustrates an open loop low speed wind tunnel that was used for testing the BWB model. 


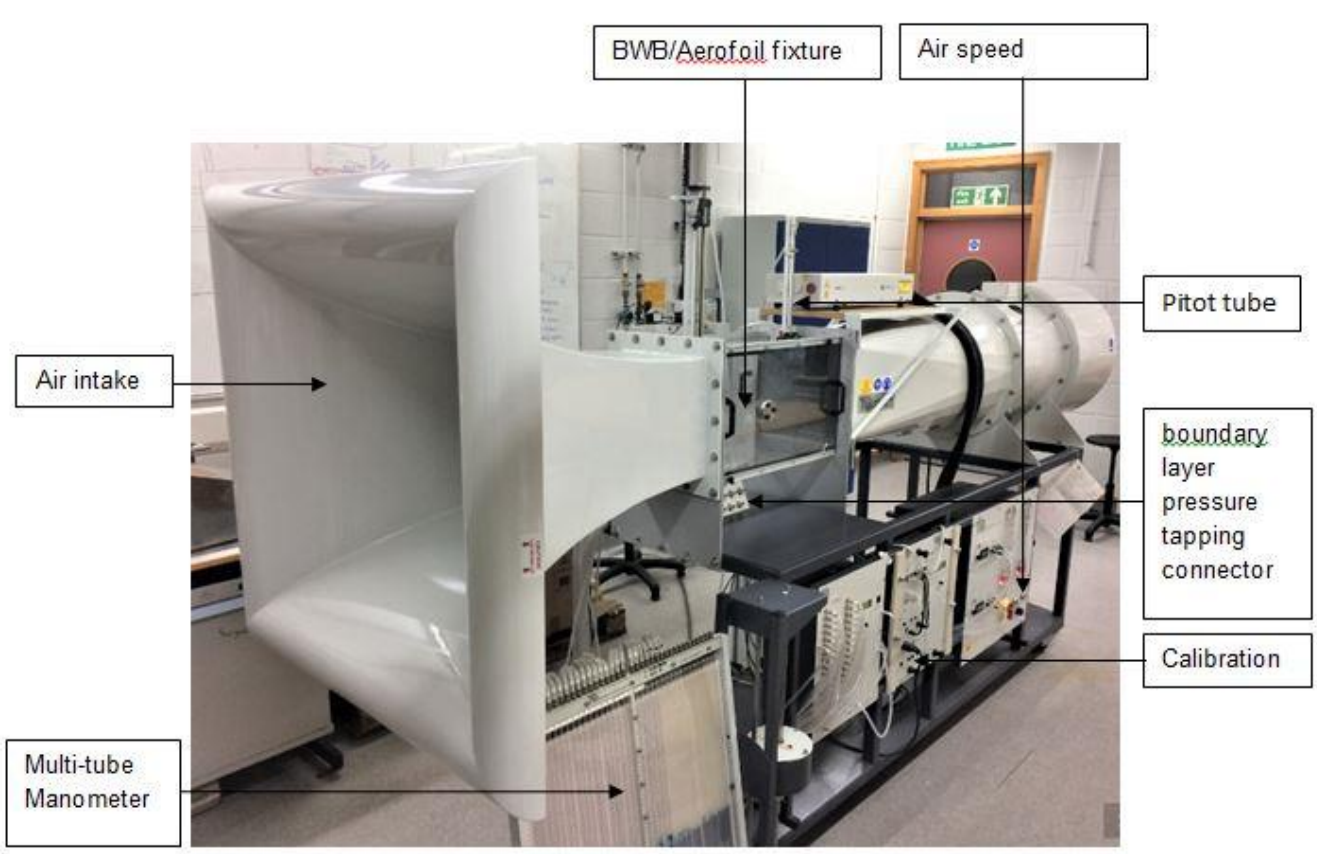

Figure 17. An open loop low speed wind tunnel that was used for testing the BWB model

\section{Methodology/Experimental Procedure}

The model was tested at $25 \mathrm{~m} / \mathrm{s}$ at angles of attack $\alpha-20^{\circ}$ to $\alpha 20^{\circ}$ at increments of $\alpha 5^{\circ}$ in an open loop wind tunnel. Once the model is set at the correct angle $\alpha^{0}$ and speed, 30 seconds is given to allow the room to equalize. The TQ data program is set to capture readings every 0.5 seconds for 15 seconds to generate a sufficient quantity of results to average. Figure18 Shows experimental run set up. 


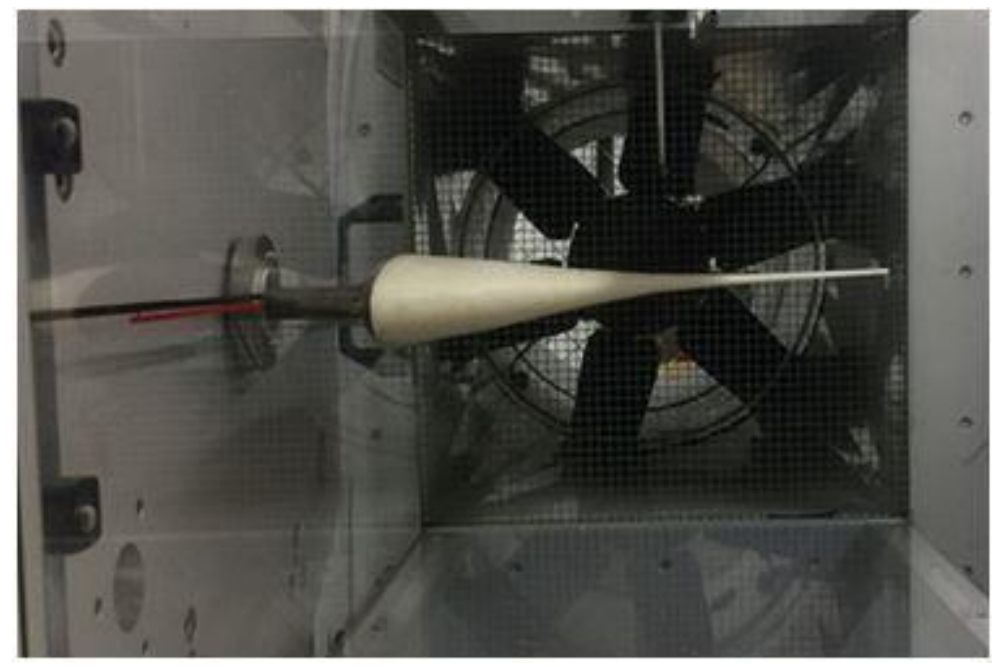

Figure18. An experimental run set up.

\section{Wind Tunnel and CFD Validation Coefficient of lift and drag.}

Figure19 compares the wind tunnel and CFD coefficient of lift and coefficient of drag results at $25 \mathrm{~m} / \mathrm{s}$. The Coefficient of Lift graph in Figure19 shows almost identical to the "CFD" simulation. The accuracy of the wind tunnel compared to CFD averages within $7.2 \%$ across all $\mathrm{Cl} / \alpha^{\circ}$ with some $\alpha^{\circ}$ being as accurate as to $0.7 \%$ away from CFD data. The information gathered from this work provides a firm understanding that the wind tunnel test validates the simulations carried out on CFD. The coefficient of drag in Figure 19b shows results from CFD simulation and the wind tunnel experiment at $25 \mathrm{~m} / \mathrm{s}$.
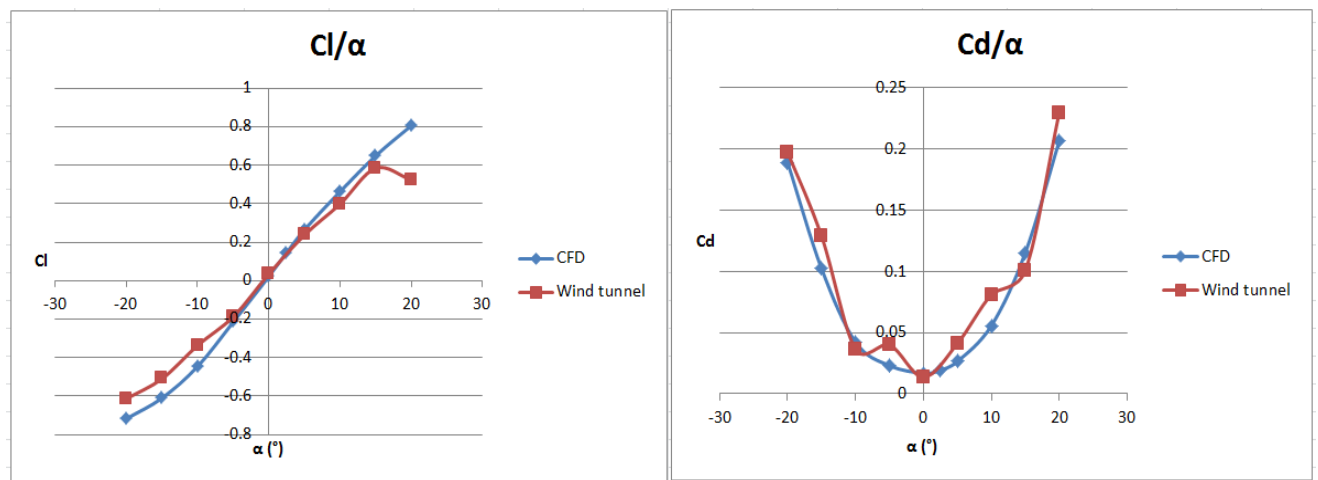

Figure 19. (a) CFD and Wind Tunnel Coefficient of Lift and Coefficient of Drag comparison; (b) CFD and Wind Tunnel Coefficient of Drag comparison 


\section{Lift to drag characteristics.}

Figure 20 shows the lift to drag ratio of the BWB from CFD simulation and Wind tunnel experiment. The maximum L/D difference from the wind tunnel to the CFD simulation is 30\%, where the wind tunnel L/D max is around 6 and the CFD $\mathrm{L} / \mathrm{D} \max$ is 10 both at $\alpha 5^{\circ}$, this optimal $\alpha^{\circ}$ is also seen by previous study (Pang Jung Hoe, 2014). The CFD simulation to experiment difference in drag coefficient of $30 \%$ is reasonable and typical for small section wind tunnel testing and for other values of $\alpha^{0}$ the difference is much smaller as illustrated by Figure 20. The lift of the BWB is within $10 \%$, suggesting that the wind tunnel is accurate and there are no parameters dramatically affecting lift.

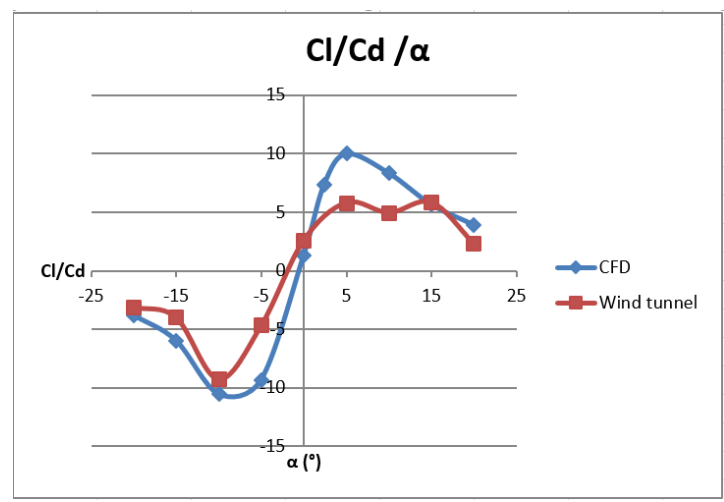

Figure 20. CFD and Wind Tunnel Coefficient of Lift to Coefficient of Drag ratio comparison.

\section{Validation and Analysis of Surface Pressure Distribution}

BWB at pressure distribution at Mach $0.6 \alpha 2.38^{\circ}$, was compared to BWB at Mach $0.85 \alpha 2.38^{\circ}$ (Kanazaki et al., 2013). Figure 21 Shows the coefficient of pressure distribution of the BWB at Mach 0.6 and Figure 22 shows BWB at Mach 0.85 . As symmetrical aerofoils are used for this BWB study, shock waves would occur if the model was simulated at Mach 0.85. Therefore, the BWB is simulated at 0.6 which will prevent the shocks and analysis can be made with and compared to design available in the public domain. The BWB in Figure 21 shows the flow of the inboard aerofoil remains attached up to approximately $85 \%$ chord where the pressure increases and separation starts to occur, the same behaviour is seen in BWB model in Figure 22. At 30\% span the pressure starts to increase up until 65\% chord where it reaches a maximum of negative value of $\mathrm{Cp} 0.89$. Between $30 \%$ and $65 \%$ span the outboard wing and centre body integrate together meaning the sudden change in geometry increases the velocity in that area which suggests why at $65 \%$ span the pressure is at its highest negative value, again the same behaviour and discussion is noted by previous study. However due to higher transonic speeds test (Kanazaki et al., 2013) experienced shocks at this point. From $45 \%$ to $65 \%$ span 
experiences a high negative pressure and then gradually increases to a positive value suggesting separation occurs right at the tip of the trailing edge. High negative pressure is seen and remains across the span of the leading edge from $65 \%$ to $100 \%$ span as expected from basic sweep theory. Looking at the lower surface of the BWB the pressure remains relatively uniform across the entire body where it gradually increases and starts to separate at the trailing edge, from $30 \%$ to $65 \%$ the pressure negatively increases as shown by the light blue contours. This behaviour shows the velocity is at its highest value at 65\% span, as expected (Revolvy, 2016; Siouris \& Qin, 2007). Overall, the BWB CFD pressure distribution follows the behaviour of previously reported (Kanazaki et al., 2013) providing certainty that the BWB has been correctly designed according to (Kanazaki et al., 2013) method.

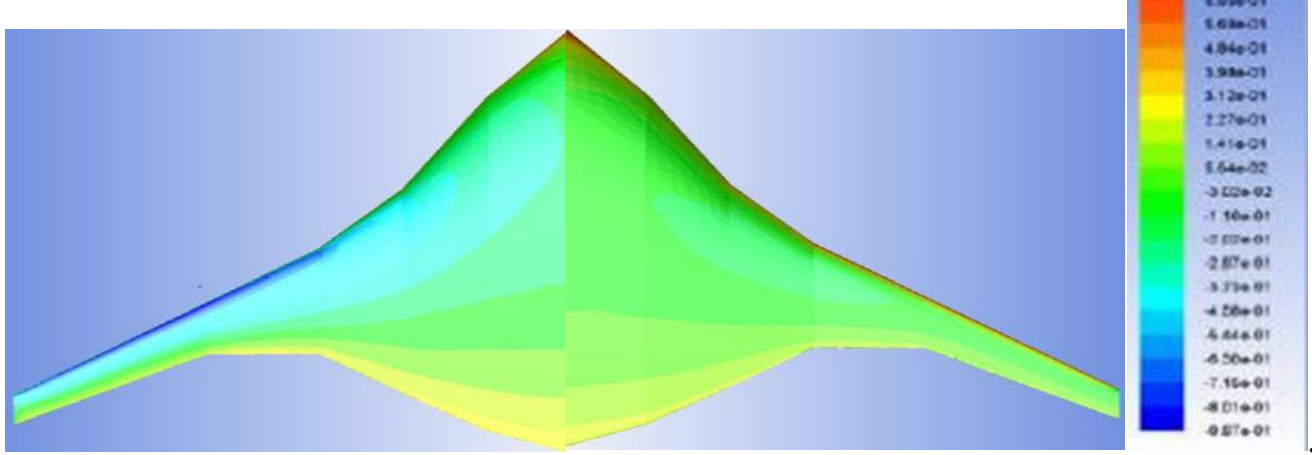

Figure 21. BWB coefficient of pressure distribution

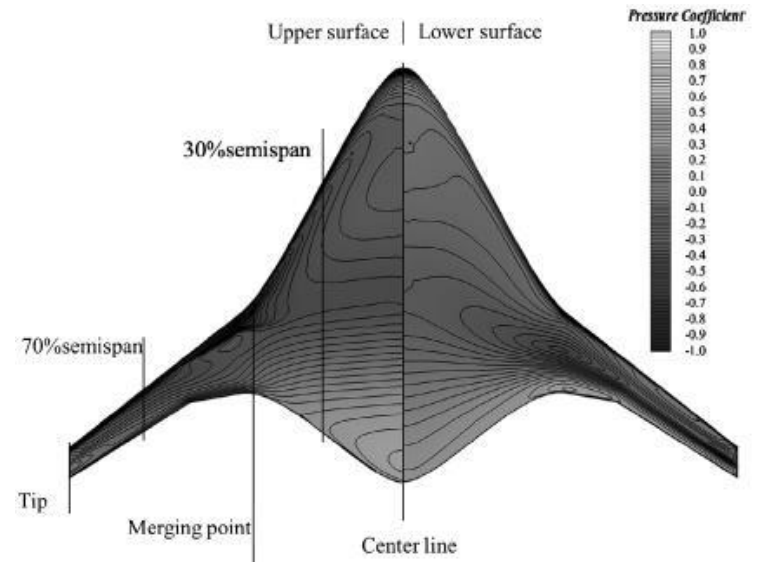

Figure 22. BWB coefficient of pressure distribution (Kanazaki et al., 2013). 


\section{$B W B$ vs conventional}

\section{CFD BWB vs conventional comparison.}

Figure 23 shows how Pang (Pang Jung Hoe, 2014) BWB L/D max is 12.54 and the BWB L/D MAX is 11.08. This analysis shows that the BWB has an L/D decrease of $11.6 \%$ compared to Pangs BWB. However, the BWB consists of a $9.4 \%$ L/D improvement over Pangs conventional comparison. This suggests that the BWB has an L/D increase over conventional aircraft of $9.4 \%$ which is considerable when saving fuel burn and cost. Overall this study has shown that the BWB performs higher than that of conventional aircraft meaning there is scope for this aircraft in the future. The reason that Pangs (Pang Jung Hoe, 2014) BWB L/D is $11.6 \%$ higher than that of the BWB is because of geometry, aerofoil, aerofoil chordwise location positioning, meshing strategy and turbulence model differences. As there were no exact dimensions stated in Pangs geometry design, it was down to scaling drawings and best judgement when positioning the aerofoils in the chordwise location meaning there will always be differences. However, $11.6 \%$ BWB to BWB difference is accurate considering the circumstances.

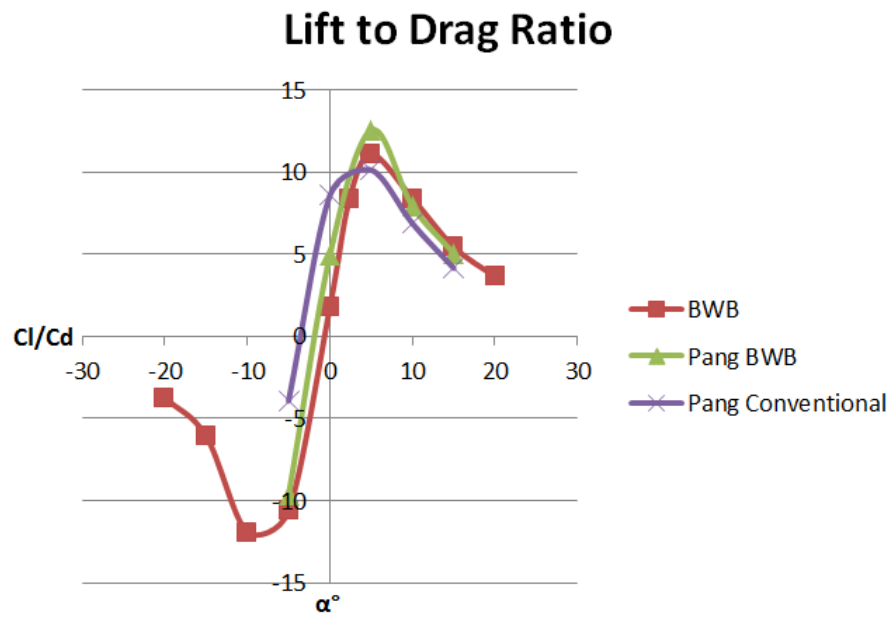

Figure 23. BWB vs conventional lift to drag ratio comparison at 0.16 Mach (60 $\mathrm{m} / \mathrm{s})$.

\section{Conclusions}

- $\quad$ This BWB study proved to have an L/D increase of $9.4 \%$ at $\alpha 5^{\circ}$ than a conventional aircraft (Tube and wing) comparison (Pang Jung Hoe, 2014). The BWB L/D value at $\alpha 5^{\circ}$ experienced in this study compared favourably with other BWB studies. 
- The CFD simulation shows that L/D max is achieved at AOA between $\alpha-5^{\circ}-\alpha 5^{\circ}$. Beyond this region of angle of attack, the lift increases slightly while the drag increases significantly.

- Comparison between CFD simulation and wind tunnel testing showed favourable results.

- Blended wing body design provides greater Aerodynamic improvements at high subsonic speeds as compared to low subsonic speeds. L/D $\max$ at $\alpha 5^{\circ}$ and Mach 0.6 increased by $12.8 \%$ compared to results captured at 60 $\mathrm{m} / \mathrm{s}$.

- $\quad$ The lift is at maximum levels at $\alpha 5^{\circ}$, where the highest negative pressure value is experienced providing a greater pressure difference between the upper and lower surfaces.

- $\quad$ The surface pressure distribution shows that at $65 \%$ span where the BWB merges with the outer wing, the velocity is at its highest (Appendix). This area is prone to shockwaves at higher Mach numbers. A smoother gradient curve interconnection between the centre body and wing tip will reduce this effect.

Overall the work has concluded that the BWB performs $9.4 \%$ better than the conventional comparison. High speed analysis has proved that the BWB performs better at high subsonic speeds; this suggests BWB would be suitable for commercial applications and could be seen in services within the next 30 years. 


\section{References}

Allen, B. A. (2008). Blended wing body - A potential new aircraft design. NASAhttp://www.nasa.gov/centers/langley/news/factsheets/FS-2003-11-81LaRC.html

ANSYS. (2006). Non-equilibrium wall functions. https://www.sharcnet.ca/ Software/ Fluent6/html/ug/node513.htm

ANSYS. (2009). Meshing - Body of nfluence. http://fernandobatista.net/ /project/Ansys12/Tutorials/PDF/MSH_BodyOfInfluence_DOC.pdf

ANSYS. (2015). Skewness definition. https://www.sharcnet.ca/Software/ Ansys/17.0/en-us/help/wb_msh/msh_skewness.html

ANSYS. (2016). Mesh quality \& advanced topics - Introduction into ANSYS meshing. http://www.ansys.com/services/training-center/platform/ introduction-to-ansys-meshing

Aurora. (2015). D8 program overview. http://www.aurora.aero/d8/

Boeing. (2013). X-48C research aircraft wraps up test flights. http://www.boeing.com/ features/2013/04/bds-x48c-04-24-13.page

Boeing. (2016). Blended wing body back to the wind tunnel. http://www.boeing.com/features/2016/09/blended-wing-body-09-16.page

Clarkson, U. (2016). The NACA airfoil series. http://people.clarkson.edu/ pmarzocc/AE429/The\%20NACA\%20airfoil\%20series.pdf

Dehpanah, P., \& Amir, N. (2015). The aerodynamic design evaluation of a blended-wing-body configuration. Aerospace Science and Technology, 96110.

DZYNE. (2016). Assent 1000. http://www.dzynetech.com/\#design-by-dzyne

Guo, Y., Burley, C., \& Thomas, R. (2014). On noise assessment for blended wing body aircraft. 52nd AIAA Aerospace Sciences Meeting (pp. 13-22). National Harbor, MD, USA: AIAA.

ICAO. (2010). Aviation outlook -Environmental report. Montreal, Canada: Author.

ICAO. (2016). Environmental report - Onboard a sustainable future. Montreal, Canada: Author.

Kanazaki, M., Hanida, R., Nara, T., Shibata, M., Nomura, T., Murayama, M., \& Yamamoto, K. (2013). Challenge of design exploration for small blended wing body using unstructured flow solver. Computers and Fluids, 71-77.

Kroo, I. (2005). Airfoil pressure distribution. http://adg.stanford.edu/aa241/ airfoils/ airfoilpressures.html

Kuntawala, N. (2011). Aerodynamic shape optimization of a blended-wing-body aircraft configuration. Toronto, Canada: Graduate Department of Aerospace Engineering, University of Toronto. 
Leibeck, R. (2004). Design of the blended wing body subsonic transport. Journal of Aircraft, 41, 10-25.

Lockheed-Martin. (2014). Carrying air mobility into the future. http://www.lockheedmartin.co.uk/us/news/features/2014/air-mobilitymove-it.html.

NASA. (2015). Lift to drag ratio. https://www.grc.nasa.gov/www/k-12/airplane/ ldrat.html

NASA. (2016). NASA takes next step in green aviation X-planes plans. https://www.nasa.gov/aero/nasa-green-aviation-X-planes

Okonkwo, P., \& Smith, H. (2016). Review of evolving trends in blended wing body aircraft design. Progress in Aerospace Sciences, 1-13.

Ordoukhanian, E., \& Madni, A. (2014). Blended wing body architecting and design: Current status and future prospects. Computer Science 2014Conference on Susytems Engineering Research (pp. 619-625).

Pang Jung Hoe, N. (2014). Numerical prediction of blended wing body aerodynamic characteristics at subsonic speed. Journal of Teknologie, 6569.

Peifeng, L. I. (2012). Aerodynamic design methodology for blended wing body transport. Chinese Journal of Aircraft, 508-516.

Qin, N., Vavalle, A., \& Moigne, A. (2005). Spanwise lift distribution for blended wing body aircraft. Journal of Aircraft, 356-365.

Qin, N., Vavalle, A., Le Moigne, A., Laban, M., Hackett, K., \& Weinerfelt, P. (2004). Aerodynamic considerations of blended wing body aircraft. Progress in Aerospace Sciences, 321-343.

Revolvy. (2016). Swept wing. https://www.revolvy.com/main/index.php?s $=$ Swept $\% 20$ wing\&item_type=topic

Saephan, S., \& Dam, C. (2008). Determination of wing-only aircraft tumbling characteristics through computational fluid dynamics. Journal Of Aircraft, 1044-1053.

Siouris, S., \& Qin, N. (2007). Study of the effects of wing sweep on the aerodynamic performance of a blended wing body aircraft. Proceedings of the Institution of Mechanical Engineers- Part G (pp. 47-55).

Thakar, N., \& Upadhyay, D. (2015). CFD analysis of aerofoil. http://www.slideshare.net/ 12neel/cfd-analysis-of-aerofoil. 


\section{Appendix}

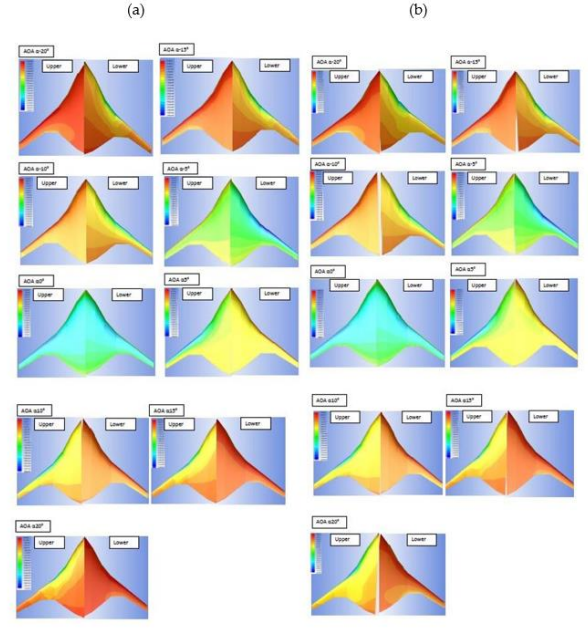

Figure A. 1a Coefficient of pressure distribution $25 \mathrm{~m} / \mathrm{s}$ at various angles of attack (-20deg to $15 \mathrm{deg}$, in $5 \mathrm{deg}$ increment); $1 \mathrm{~b}$ Coefficient of pressure distribution 60 $\mathrm{m} / \mathrm{s}$ at various angles of attack (-20deg to $15 \mathrm{deg}$, in $5 \mathrm{deg}$ increment). 